\title{
Determinants of exceptional human longevity: new ideas and findings
}

\author{
Leonid A. Gavrilov and Natalia S. Gavrilova*
}

\begin{abstract}
Studies of centenarians are useful in identifying factors leading to long life and avoidance of fatal diseases. In this article we consider several approaches to study effects of early-life and midlife conditions on survival to advanced ages: use of non-biological relatives as controls, the within-family analysis, as well as a sampling of controls from the same population universe as centenarians. These approaches are illustrated using data on American centenarians, their relatives and unrelated shorterlived controls obtained from the online genealogies. The within-family analysis revealed that young maternal age at person's birth is associated with higher chances of exceptional longevity. Comparison of centenarians and their shorter-lived peers (died at age 65 and sampled from the same pool of online genealogies) confirmed that birth timing in the second half of the calendar year predicts survival to age 100 . Parental longevity as well as some childhood and midlife characteristics also proved to be significant predictors of exceptional longevity.
\end{abstract}

\section{Introduction}

Studies of centenarians (people living to 100 and older) could be useful in identifying factors leading to long life and avoidance of fatal diseases. Even if some individual characteristics have a moderate protective effect on the risk of death, people with this trait/condition should be accumulated among long-lived individuals, because of cumulative survival advantage. Thus, studying centenarians may be a sensitive way to find genetic, familial, environmental and life-course factors associated with lower mortality and better survival.

Most studies of centenarians in the United States are focused on either genetic (Hadley et al. 2000; Murabito et al. 2012; Perls and Terry 2003; Sebastiani et al. 2012; Zeng et al. 2010) or psychological (Adkins et al. 1996; Hagberg et al. 2001; Margrett et al. 2010; Martin et al. 2010; Murabito et al. 2012) aspects of survival

* Leonid A. Gavrilov (correspondence author), Center on Aging, NORC at the University of Chicago, USA. Email: gavrilov@ longevity-science.org

Natalia S. Gavrilova, Center on Aging, NORC at the University of Chicago, USA. 
to advanced ages. On the other hand, several studies suggest that early-life events and conditions may have significant long-lasting effects on survival to advanced ages (Barker 1998; Costa and Lahey 2005; Elo and Preston 1992; Finch and Crimmins 2004; Fogel and Costa 1997; Gavrilov and Gavrilova 2001a; Gavrilov and Gavrilova 2003a; Gavrilov and Gavrilova 2003b; Gavrilov and Gavrilova 2006; Hayward and Gorman 2004; Kuh and Ben-Shlomo 1997; Smith et al. 2009b).

Studies of centenarians can provide important contributions to this area of research. However, they require serious work on age validation (Jeune and Vaupel 1999; Poulain 2010; Poulain 2011) and careful design including the choice of an appropriate control group. Living to age 100 is a rare event, and it is very difficult to obtain a representative population sample of centenarians for a large country as the United States. Nevertheless, use of general population as a control group is one of the most popular approaches in centenarian studies (Jarry et al. 2012a; Montesanto et al. 2011; Perls et al. 2007; Willcox et al. 2006). We used this approach in our prior study of early-life conditions and longevity (Gavrilova and Gavrilov 2007). In that investigation we assumed that persons in computerised family histories did not differ from the general population and found some agreement with other studies (Hill et al. 2000; Preston et al. 1998). However, there is still a possibility of obtaining biased results if this assumption is not true. For this reason, better research approaches to centenarian studies should be developed as they are described below.

In this article we consider several approaches to study effects of early-life conditions on survival to advanced ages which use more appropriate control groups compared to the population-based control. These approaches include: (1) use of nonbiological relatives, such as siblings-in-law, as a control group, (2) the within-family analysis and (3) the between-family analysis with selection of controls from the same population universe. These approaches are used in the study of early-life and midlife predictors of exceptional longevity in the United States. For our studies we use family histories (genealogies) which proved to be a good source of information for different types of relatives and have successfully been used in historical demography (Adams and Kasakoff 1984; Anderton et al. 1987; Bean et al. 1992) and biodemography (Caselli et al. 2006; Gavrilov et al. 2002; Gavrilova et al. 1998; Smith et al. 2009a; Smith et al. 2009b).

\section{Comparative study of biological and non-biological relatives}

Numerous studies found that biological relatives of long-lived individuals have substantial survival advantage compared to relatives of shorter-lived individuals (Gavrilov and Gavrilova 2001b; Gavrilov et al. 2002; Kerber et al. 2001; Pearl and Pearl 1934; Perls et al. 2007; Smith et al. 2009a; Willcox et al. 2006), while relatively few studies have analysed the lifespan of non-biological relatives (Jarry et al. 2012a; Mazan and Gagnon 2007; Montesanto et al. 2011; Schoenmaker et al. 2006; 
Table 1:

Number of centenarians and their siblings at different stages of data collection and cleaning

\begin{tabular}{|c|c|c|c|c|}
\hline \multirow[b]{2}{*}{ Type of records } & \multicolumn{3}{|c|}{ Number of centenarians } & \multirow{2}{*}{$\begin{array}{c}\text { Number of } \\
\text { siblings }\end{array}$} \\
\hline & Males & Females & Total & \\
\hline $\begin{array}{l}\text { All initial non-duplicate records } \\
\text { for centenarians born in } \\
1880-1895 \text { with names of } \\
\text { parents available }\end{array}$ & 7,174 & 18,277 & 25,451 & \\
\hline $\begin{array}{l}\text { Centenarians having detailed } \\
\text { information on birth and death } \\
\text { dates of their parents }\end{array}$ & 6,370 & 16,757 & 23,127 & 172,091 \\
\hline $\begin{array}{l}\text { Centenarians having detailed } \\
\text { information on birth and death } \\
\text { dates of their parents and } \\
\text { siblings }\end{array}$ & 707 & 2,127 & 2,834 & 21,893 \\
\hline $\begin{array}{l}\text { Centenarians with confirmed death } \\
\text { dates through the linkage to US } \\
\text { Social Security Death Master } \\
\text { File, DMF, having detailed } \\
\text { information on birth and death } \\
\text { dates of their parents and } \\
\text { siblings }\end{array}$ & 398 & 1,313 & 1,711 & 13,295 \\
\hline
\end{tabular}

Westendorp et al. 2009). Besides being an interesting population sub-group for the study of longevity, non-biological relatives may serve as a nonbiased environmental control group for centenarians in contrast to the general population.

In general, studies of biological and non-biological relatives deal with relatively small case numbers. In our study we intended to create a large sample of centenarians and their siblings. Therefore, we conducted a large-scale search in many hundreds of online family histories using a technique known as 'web automation' (Sklar and Trachtenberg 2002). This technique allowed us to search online databases for people with exceptional longevity (and some other traits). Table 1 shows the steps of data collection and the number of records obtained in each stage of data collection. In a first step we scanned more than 300,000 publicly available online databases in the Rootsweb WorldConnect project (http://wc.rootsweb.ancestry.com). This search led to the identification of 25,451 non-duplicate records of alleged centenarians born between 1880 and 1895 with available information about names of their parents.

The next step was to collect detailed data on the parents of the centenarians from computerised genealogies using the same web-automation technique. After this 
procedure, we selected the most detailed genealogies where information on birth and death dates for both parents was available. Our prior experience in working with computerised genealogies suggests that this procedure selects-out the majority of genealogies with poor quality. As a result of this procedure, the total number of centenarian records decreased to 23,127 . In the next step, we collected data on 172,091 siblings for those centenarians who had detailed data on parental birth and death dates. However, a significant proportion of these records did not contain information about the death dates, which created some difficulties for our withinfamily study of human longevity (described in the next section). Hence, the next step was to identify the most detailed family histories of families with complete information on birth and death dates for siblings. As a result of this identification procedure, we found 2,834 families for which information on birth and death dates was known for more than 80 per cent of siblings. Finally, the age at death of centenarians in our sample was verified using the US Social Security Administration Death Master File (DMF). This procedure confirmed the age for 1,711 centenarians born in the years 1880 to $1895 .^{1}$

The final database of centenarians and their relatives contains information on lifespan for 398 male and 1,313 female centenarians, their 13,295 siblings, 1,307 spouses and 7,924 siblings-in-law. Lifespan information was collected for all siblings of centenarians who did not die in childhood. Completeness of lifespan information was $76 \%$ for spouses of centenarians and $82 \%$ for siblings-in-law. These data formed the basis of our comparative analysis of longevity using different types of biological and non-biological relatives. Although the studied sample of centenarians is not representative, it is useful for analytical studies of early-life conditions and longevity when appropriate control groups are available (Woodward 2005). ${ }^{2}$

Comparison of the mean lifespan for relatives who survived to age 50 reveals a survival advantage of brothers and sisters of centenarians compared to the same-sex siblings-in-law. As shown in Table 2, brothers lived 2.6 years longer and sisters lived even 2.9 years longer on average compared to siblings-in-law of the same sex, with the differences in lifespan being statistically significant $(\mathrm{p}<0.001)$.

Wives of centenarians tend to live 0.8 year less on average than married sisters of centenarians; however this difference is not statistically significant. Husbands of centenarians live 2.3 years less on average than married brothers of centenarians

\footnotetext{
1 In a previous study we found that the ages of centenarians confirmed by linking to the DMF are confirmed through the linkage to early US censuses in more than 98 per cent of cases (Gavrilova and Gavrilov 2007). Thus, there is not a strong need to carry out any additional verification with the early census records.

2 For instance, the sibship size of the centenarian families was larger than that of the general population. This can be explained by the fact that genealogies are more likely to be compiled for larger families and that longer-lived individuals in the United States were born more often in rural areas with higher fertility (Gavrilova and Gavrilov 2007; Preston et al. 1998). However, it should be noted that this difference in sibship size with the general population is not critical for the within-family design of the study when the shorter-lived siblings raised in the same family or spouses are used as control group.
} 
Table 2:

Mean lifespan conditional on survival to age 50 (LS50) with $95 \%$ confidence intervals (95\% CI) for relatives of centenarians (compared to the 1900 US birth cohort)

\begin{tabular}{lrcrrrr}
\hline & \multicolumn{2}{c}{ Male relatives } & & \multicolumn{2}{c}{ Female relatives } \\
\cline { 2 - 3 } \cline { 6 - 7 } Relatives of centenarians & $\begin{array}{c}\text { Sample } \\
\text { size, } \boldsymbol{N}\end{array}$ & $\begin{array}{c}\text { LS50 (95\% CI) } \\
\text { years }\end{array}$ & & $\begin{array}{c}\text { Sample } \\
\text { size, } \boldsymbol{N}\end{array}$ & $\begin{array}{c}\text { LS50 (95\% CI), } \\
\text { years }\end{array}$ \\
\hline Parents & 1590 & $76.2(75.7-76.8)$ & & 1557 & $77.2(76.7-77.8)$ \\
All siblings & 5324 & $77.6(77.3-77.9)$ & & 4877 & $82.4(82.0-82.7)$ \\
Married siblings & 3221 & $77.7(77.3-78.1)$ & & 3028 & $82.2(81.8-82.6)$ \\
Spouses & 876 & $75.4(74.6-76.1)$ & & 283 & $81.4(80.1-82.7)$ \\
Siblings-in-law & 2349 & $75.0(74.6-75.5)$ & & 2407 & $79.5(79.0-79.9)$ \\
1900 US birth cohort & & 73.3 & & & 79.4 \\
\hline
\end{tabular}

$(\mathrm{p}<0.001)$. Although fathers of centenarians were born about 30 years earlier than brothers-in-law of centenarians they still have a longer lifespan conditional on survival to age 50 than later-born non-biological relatives such as siblings-in-law $(\mathrm{p}<0.001)$ and husbands of centenarians $(\mathrm{p}=0.04)$. On the other hand, mothers of centenarians who survived to age 50 have the shortest lifespan among all relatives77.2 years on average. This is, however, most likely related to the physiological burden of childbearing in these large families, as mothers of many children have been shown to have increased mortality (Dior et al. 2013; Gagnon et al. 2009; Riley 2003). Thus, excluding the mothers of centenarians we can conclude that siblings-in-law have a shorter lifespan than biological relatives and spouses born in a similar time period. This result probably reflects the fact that siblings-in-law are lacking certain genetic or environmental advantages that other relatives have.

At the same time, the lifespan of siblings-in-law is still higher than the mean lifespan of the general population, i.e. the 1900 US birth cohort (Bell et al. 1992). This difference is particularly high for men -1.7 years $(p<0.001)$ while for women it is not statistically significant (Table 2). This finding is particularly important because it indicates that comparing the survival of siblings or other biological relatives of centenarians to the general population may overstate their survival advantage and hence overestimate the genetic contribution to lifespan. Thus, the using the general population to compare survival of relatives of long-lived individuals may be inappropriate, especially for males. Therefore siblings-in-law appear to be a more appropriate control group than the general population.

Although the positive association of a person's longevity with better survival of biological relatives is well documented, little is known about the effects of a centenarian's gender on longevity of biological and non-biological relatives. Table 3 shows that fathers of male centenarians lived significantly longer than fathers of female centenarians: the mean lifespans conditional on survival to age 
Table 3:

Mean lifespan conditional on survival to age 50 (LS50) for biological and non-biological relatives of centenarians, by gender of centenarian

\begin{tabular}{|c|c|c|c|c|c|}
\hline \multirow[b]{2}{*}{ Type of relative } & \multicolumn{2}{|c|}{$\begin{array}{c}\text { Relatives of } \\
\text { male centenarians }\end{array}$} & \multicolumn{2}{|c|}{$\begin{array}{c}\text { Relatives of } \\
\text { female centenarians }\end{array}$} & \multirow[b]{2}{*}{ p-value ${ }^{\dagger}$} \\
\hline & $\begin{array}{c}\text { Sample } \\
\text { size } N\end{array}$ & $\begin{array}{l}\text { LS50, } \\
\text { years }\end{array}$ & $\begin{array}{c}\text { Sample } \\
\text { size } N\end{array}$ & $\begin{array}{l}\text { LS50, } \\
\text { years }\end{array}$ & \\
\hline \multicolumn{6}{|l|}{ Parents } \\
\hline Fathers & 374 & 77.22 & 1216 & 75.93 & 0.023 \\
\hline Mothers & 362 & 77.96 & 1195 & 77.03 & 0.087 \\
\hline \multicolumn{6}{|l|}{ Siblings } \\
\hline Brothers & 1268 & 79.25 & 4056 & 77.09 & $<0.001$ \\
\hline Sisters & 1071 & 82.06 & 3806 & 82.45 & 0.836 \\
\hline \multicolumn{6}{|l|}{ Siblings-in-law } \\
\hline Brothers-in-law & 492 & 74.00 & 1857 & 74.55 & 0.577 \\
\hline Sisters-in-law & 611 & 79.22 & 1796 & 79.55 & 0.730 \\
\hline
\end{tabular}

${ }^{\dagger} \mathrm{p}$-values are related to the difference between lifespans of corresponding relatives of male vs female centenarians.

50 were 77.22 years vs 75.93 years $(\mathrm{p}=0.023)$. This effect is gender-specific, as it is not observed for mothers of male centenarians (who show similar survival rates as mothers of female centenarians). Brothers of male centenarians also lived significantly longer compared to brothers of female centenarians: the mean lifespans conditional on survival to age 50 were 79.25 and 77.09 years respectively $(p<0.001)$. Again, this effect is gender-specific. Sisters of female centenarians have no statistically significant survival advantage over sisters of male ones (82.45 vs 82.06 years, $\mathrm{p}=0.836$ ).

The survival advantage of brothers of male centenarians might be explained by a stronger genetic influence on male longevity. This hypothesis is supported by a recent study of Montesanto et al. (2011) on 202 nonagenarians born around 1910 and their relatives in the province of Calabria in Italy which found similar-albeit not identical-indications for the existence of a genetic longevity advantage in males. Nevertheless, although both studies point to genetic factors as an explanation of the observed effects of male centenarian gender, we need to consider alternative nongenetic explanations as well. Taking into account that female gender of a centenarian has a much weaker effect on the survival of her sisters compared to the effect of male centenarian gender on the survival of his brothers, we may hypothesise that male centenarians and their brothers share specific living conditions and lifestyle. This favourable lifestyle could originate from their fathers, whose trades and occupations were often inherited by sons in the past (Ruggles 2007). For example, farming is beneficial for longevity (Gavrilov and Gavrilova 2012) and it is reasonable to assume 
that brothers of male centenarians shared the farming occupation of their long-lived brothers. This explanation is also consistent with our previous results as well as results of other studies which found positive effects of farming and farm background on late-life survival (Gavrilova and Gavrilov 2007; Preston et al. 1998).

Additional support for this hypothesis is provided by data on mean lifespan for siblings-in-law of centenarians. Siblings-in-law do not share the specific genes and family-of-origin environments with centenarians but they usually come from a similar socio-economic background (because of assortative mating). Table 3 includes the mean lifespans conditional on survival to age 50 years for siblings and siblings-in-law of centenarians depending on centenarian gender. The data reveal that centenarian gender has no effect on life expectancy of siblings-in-law. This indicates that the survival advantage of brothers of male centenarians is not related to a better socioeconomic status of families of male centenarians but rather to gender-specific positive effects of living conditions and lifestyle shared by brothers of male centenarians.

Further support for the importance of favourable living conditions and/or lifestyles of male centenarians is presented in Table 4 which shows that the wives of centenarians live significantly longer than sisters-in-law of centenarians (i.e. wives of brothers of centenarians). In contrast, husbands of centenarians do not demonstrate this survival advantage. ${ }^{3}$ Thus, our study suggests that a significant portion of the higher lifespan of siblings of centenarians may be related to healthier lifestyles and living conditions rather than purely to genetic effects because otherwise wives of centenarians would not benefit from their husbands' longevity.

Nevertheless, possible explanations for the better survival shown by the brothers of male centenarians are not limited to those described in this section. Further analyses of living conditions during the adult years (taken from early censuses) of brothers of centenarians may shed an additional light on the causes of this interesting phenomenon.

\section{Centenarians compared to their shorter-lived siblings: the within-family approach}

A promising approach to the choice of control group in studies of centenarians looks at their shorter-lived siblings. This within-family approach allows researchers to eliminate between-family variation including the differences in genetic background and childhood living conditions (Woodward 2005). Within a family, children are born to parents at different ages and this variation may be used to estimate the net effect of parental age more conclusively (Kalmijn and Kraaykamp 2005). Similarly,

\footnotetext{
3 In contrast to our findings, a study of Canadian centenarians reports an equal (and relatively large) gain in life expectancy for both wives and husbands of centenarians compared to the general population (Jarry et al. 2012a). It should be noted, however, that these results are based on comparisons to the general population, which might overstate the male survival advantage as discussed in this section.
} 
Table 4:

Mean lifespan conditional on survival to age 50 (LS50) for spouses of centenarians and spouses of siblings of centenarians, by gender

\begin{tabular}{lrrrrrr}
\hline & \multicolumn{2}{c}{ Spouses of centenarians } & & \multicolumn{2}{c}{ Spouses of siblings of centenarians } & \\
\cline { 2 - 3 } Relatives & Sample size $\boldsymbol{N}$ & LS50, years & & Sample size $\boldsymbol{N}$ & LS50, years & p-value \\
\hline Husbands & 876 & 75.38 & & 2349 & 75.04 & 0.221 \\
Wives & 283 & 81.40 & & 2407 & 79.46 & 0.004 \\
\hline
\end{tabular}

${ }^{\dagger}$ p-value is related to the difference between mean lifespan of spouses of centenarians vs spouses of siblings of centenarians.

we can estimate the net effects of other early-life factors, such as birth months, on longevity. We based the analysis on our sample of the families of 1,711 centenarians as described in the previous section (see Table 1) to explore the effects of several early-life factors on the likelihood of survival to advanced ages. Some siblings of these centenarians were born after 1910 and still living, therefore their death dates were not indicated (hence, they could potentially become centenarians). To avoid this kind of data truncation, we used only those centenarians who were born between 1880 and 1889 as for this subgroup there were no siblings born after 1910 with unknown death dates (all siblings were born between 1850 and 1910). This procedure decreased our study sample to 1,081 centenarians and 7,520 siblings.

The statistical analyses of within-family effects are performed using a conditional multiple logistic regression model (fixed-effect model) to investigate the relationship between an outcome of being a case (long-lived person) and a set of explanatory variables (Breslow and Day 1993; Hosmer and Lemeshow 2001). The likelihood to survive to advanced ages (i.e. to be in the long-lived group) is used as a dependent variable. ${ }^{4}$ Analyses were conducted using Stata Statistical Software, Release 11 (StataCorp 2009). In the analyses we used only those families in which both parents had lived 50 years and more and hence were able to realise their reproductive potential. We included the role of the paternal age of reproduction as a potential predictor for survival to age 100. When the first child is born, the father is younger and can provide resources for a longer period than for his later-born children (Smith et al. 2009b). Thus, the following variables were included in the model: birth order, paternal age, maternal age, month of birth and sex.

We found no statistically significant effects of birth order on the chances to survive to advanced ages in this particular data sample when parental age was also included in the analysis (data not shown). At the same time, persons born in October-November showed higher (and statistically significant) chances to become

4 Variation between the estimates of effect from each family (heterogeneity) does not affect the confidence interval in a fixed-effect model. 
Table 5:

Effects of maternal age at a person's birth on human longevity. Odds ratios (with p-values) to live to 100 as predicted by conditional logistic regression (fixed effects) ${ }^{\dagger}$

\begin{tabular}{|c|c|c|c|c|}
\hline Variable & Model 1 & Model 2 & $\begin{array}{l}\text { Model } 3 \\
\text { Mother lived } \\
<80 \text { years }\end{array}$ & $\begin{array}{l}\text { Model } 4 \\
\text { Mother lived } \\
\text { 80+ years }\end{array}$ \\
\hline \multicolumn{5}{|l|}{ Maternal age: } \\
\hline$<20$ & $1.79(0.009)$ & $1.73(0.031)$ & $1.61(0.118)$ & $2.01(0.035)$ \\
\hline $20-24$ & $1.82(<0.001)$ & $1.79(0.002)$ & $1.87(0.006)$ & $1.71(0.027)$ \\
\hline $25-29$ & $1.67(0.002)$ & $1.65(0.004)$ & $1.65(0.024)$ & $1.64(0.035)$ \\
\hline $30-34$ & $1.35(0.067)$ & $1.34(0.093)$ & $0.98(0.930)$ & $1.84(0.009)$ \\
\hline $35-39$ & $1.19(0.311)$ & $1.18(0.345)$ & $1.11(0.663)$ & $1.25(0.366)$ \\
\hline $40+$ & Reference & Reference & Reference & Reference \\
\hline \multicolumn{5}{|c|}{$\begin{array}{l}\text { Paternal age } \\
\quad \text { (age group 25-49 } \\
\text { used as a reference) }\end{array}$} \\
\hline$<25$ & & $1.05(0.775)$ & & \\
\hline $50+$ & & $0.97(0.896)$ & & \\
\hline Female sex & $3.28(<0.001)$ & $3.28(<0.001)$ & $3.21(<0.001)$ & $3.43(<0.001)$ \\
\hline \multicolumn{5}{|l|}{ Born in } \\
\hline October-November & $1.32(0.009)$ & $1.32(0.009)$ & $1.20(0.234)$ & $1.47(0.010)$ \\
\hline Pseudo $\mathrm{R}^{2}$ & 0.0715 & 0.0716 & 0.0724 & 0.0789 \\
\hline $\begin{array}{l}\text { Number of } \\
\text { observations }\end{array}$ & 6,023 & 6,023 & 3,198 & 2,825 \\
\hline
\end{tabular}

${ }^{\dagger}$ Calculated using Stata 11 statistical package (procedure clogit).

centenarians (Gavrilov and Gavrilova 2011). Therefore this variable (birth in OctoberNovember) was included in the regression model. With regard to parental age at reproduction we found that siblings born to fathers younger than 40 years had higher chances to survive to 100 than siblings born to older fathers (50 and older). However, control for maternal age decreased this dependence and made it statistically insignificant. This suggests that the apparent effects of a young paternal age on exceptional longevity are driven by the correlated effects of a young mother. For this reason, we focused our study on the effects of maternal age on longevity.

In the multivariate analysis it turned out that a young maternal age at childbirth was the most important predictor of exceptional survival (Table 5, Model 1), while the effects of paternal age at birth became statistically insignificant (Table 5, Model 2). The odds to live to 100 are 1.6 times higher for children born to younger mothers compared to siblings (brothers and sisters) born to mothers older than age 40 in the same families and even after controlling for paternal age.

One possible explanation for the observed effects of maternal age on longevity is related to the length of mothering (i.e. the duration of maternal care and supervision). Children born to young mothers (under 25 years) are exposed to maternal care for 
Table 6:

Effects of maternal age on human longevity. Odds ratios (with p-values) to live to 100 as predicted by conditional logistic regression (fixed effects) for different subgroups ${ }^{\dagger}$

\begin{tabular}{lllll}
\hline & $\begin{array}{l}\text { Siblings } \\
\text { survived } \\
\text { to age 50 }\end{array}$ & $\begin{array}{l}\text { Siblings } \\
\text { survived } \\
\text { to age 70 }\end{array}$ & $\begin{array}{l}\text { Siblings survived } \\
\text { to age 20; smaller } \\
\text { family size }(<9)\end{array}$ & $\begin{array}{l}\text { Siblings survived } \\
\text { to age 20; larger } \\
\text { family size }(9+)\end{array}$ \\
\hline $\begin{array}{l}\text { Maternal age: } \\
\quad 20\end{array}$ & $1.84(0.009)$ & $1.87(0.008)$ & $2.99(0.004)$ & $1.48(0.178)$ \\
$20-24$ & $1.75(0.001)$ & $1.73(0.002)$ & $2.27(0.004)$ & $1.49(0.057)$ \\
$25-29$ & $1.55(0.008)$ & $1.55(0.011)$ & $1.63(0.078)$ & $1.54(0.033)$ \\
$30-34$ & $1.33(0.093)$ & $1.28(0.159)$ & $1.12(0.690)$ & $1.47(0.061)$ \\
$35-39$ & $1.13(0.504)$ & $1.09(0.637)$ & $1.21(0.511)$ & $1.06(0.784)$ \\
$40+$ & Reference & Reference & Reference & Reference \\
$\begin{array}{l}\text { Female sex } \\
\text { Born in }\end{array}$ & $3.32(<0.001)$ & $3.03(<0.001)$ & $3.58(<0.001)$ & $3.14(<0.001)$ \\
October-November & $1.29(0.019)$ & $1.27(0.033)$ & $1.20(0.284)$ & $1.39(0.019)$ \\
Pseudo R & 0.0773 & 0.0692 & 0.0953 & 0.0662 \\
Number of observations & 4,748 & 3,952 & 1,896 & 3,388 \\
\hline
\end{tabular}

${ }^{\dagger}$ Calculated using Stata 11 statistical package (procedure clogit).

a longer time on average than later-born offspring, which may explain detrimental effects of old maternal age on longevity (Gavrilov and Gavrilova 2012; Myrskylä and Fenelon 2012). In our study of long-lived families we may expect weaker effects of maternal age on longevity for offspring of long-lived mothers, because these mothers have a substantial lifespan overlap even with their late-born children. Therefore we performed regression analyses separately for long-lived mothers (who lived 80 years and more) and mothers who lived less than 80 years (Table 5, Models 3 and 4). The results show, however, that maternal age effects on longevity for offspring of short-lived mothers (Table 5, Model 4) are not stronger compared to these effects in the offspring of long-lived mothers as it would be predicted by the mothering hypothesis.

Our next research question concerned the role of child mortality, which was very high a century ago, when the studied centenarians were born. To avoid the effects of child mortality on survival, we re-analysed our data including only those siblings who survived to older ages. We found that for siblings who survived to age 50, younger maternal age remains a significant predictor of longevity: the odds to live to 100 are 1.84 times higher for siblings born to mothers younger than 20 years compared to siblings born to 40-year-old mothers (Table 6). Moreover, even after age 70 being born to a young mother still has a significant impact on longevity: the odds to celebrate the 100th birthday are 1.9 times higher for siblings born to mothers younger than 20 years compared to those born to 40 -year-old mothers. 
Another interesting aspect is the effect of family size. In our dataset, families are rather large with a median size of nine children and some families having up to 18 children while at the same time, contemporary families in the United States were significantly smaller (see also Section 1). To investigate the effects of family size, we sub-divided families in which centenarians were born into smaller families (with less than nine children) and larger families (with nine children and more). ${ }^{5}$ We found that the effect of maternal age on survival is stronger in smaller families than in larger ones. In smaller families, siblings born to mothers younger than 20 years had almost three times higher chances to live to 100 compared to their brothers and sisters born to 40-year-old mothers (Table 6).

The reasons for stronger effects of maternal age on longevity in smaller families are not clear, but some clues can be found in a Swedish study on birth order and mortality (Modin 2002). This study of adult mortality found that "a hump-shaped association appears to exist for both men and women, with first and very late borns having approximately the same mortality risk" (Modin 2002, p. 1059), whereas individuals with intermediate birth orders (3-6) had the highest risk of death at adult age. The author of this study suggests that "older brothers and sisters may serve as role models for younger siblings, and they are often important sources of social support" (Modin 2002, pp. 1051-52). Therefore, "it is possible that, at adult and old age, having a large number of [older] siblings acts as a buffer against ill health and mortality by means of greater access to social support from the family of origin" (Modin 2002, p. 1059). As children of older mothers in large families have high birth orders it is possible that detrimental effects of old maternal age on late-life mortality in these families can be partially alleviated by additional support and positive influence of older siblings on health. As a result, the inverse relationship between maternal age and longevity in large families may be weaker, as found in our analysis. Also Jalavisto (1950) found negative effects of maternal age on longevity using genealogies of Finnish and Swedish middle class and aristocracy. Finally, this relationship was confirmed by Kemkes-Grottenthaler (2004) who also found that the lifespan of children decreased with increasing maternal age.

Studies on the long-term effects of maternal age in human beings based on the between-family approach produced some inconsistent results. For instance, our earlier studies found a negative effect of maternal age on lifespan of daughters using genealogical data on predominantly Russian nobility (Gavrilov et al. 1997), while no association of maternal age with offspring mortality was found for historical populations of European aristocracy (Gavrilov and Gavrilova 2000). Studies of parental age in the Canadian population and a sample of French centenarians found no link between parental age and longevity (Hubbard et al. 2009; Robine et al. 2003). An analysis of survival by Myrskylä and Fenelon (2012) using the US Health and Retirement Study cohort found that the offspring born to mothers aged 25-35 years demonstrated better survival and health at older ages compared to children of younger

5 It should be noted that in many larger families, some siblings died in infancy or early childhood. 
and older mothers. The authors of this study showed that negative effects of older (but not younger) mothers were alleviated by controlling for maternal education and the age at which a child lost its mother.

The within-family analysis of the paternal- and maternal-age effects on human longevity demonstrated that a young age of the mother increases the chances of children to reach longevity (see also Gavrilov and Gavrilova 2012; Gavrilova and Gavrilov 2007; Jarry et al. 2012b; Myrskylä et al. 2013). The finding of a beneficial effect of young maternal age on offspring survival to age 100 in humans is similarly also reported for laboratory animals (Carnes et al. 2012; Tarin et al. 2005), and hence may have a biological explanation. There is empirical evidence that the quality of female eggs in humans rapidly declines with age (Bickel 2005; Pellestor et al. 2005; Comings and MacMurray 2001; Comings and MacMurray 2006) and that this deterioration starts rather early-before age 30 (Heffner 2004). Another plausible biological hypothesis is the telomere theory of reproductive senescence in females (Keefe et al. 2005), which posits that eggs ovulating from older females have shorter telomeres because of late exit from the oogonial 'production line' during foetal life (Polani and Crolla 1991), with incomplete restoration by telomerase (Keefe et al. 2005). Maternal age also influences the biology of the mother-foetus relationship, with a negative effect on foetal development and predisposition to severe diseases such as type 1 diabetes (Gloria-Bottini et al. 2005).

However, in human beings, some additional socio-behavioural mechanisms may also be involved, on top of more general biological mechanisms. One such mechanism may be the positive effects of prolonged maternal care on health and longevity or the above mentioned mothering hypothesis (Gavrilova and Gavrilov 2007). In contrast, as already described, Myrskylä and Fenelon (2012) believe that the observed relationship between maternal age and mortality is most likely explained by the effects of early maternal loss among the children of old mothers rather than physiological mechanisms related to maternal ageing. They also believe that previous studies inadequately controlled for maternal socio-economic characteristics or lifespan overlap. Our study does not agree with this conclusion, however. The overwhelming majority of mothers in our sample were housewives who finished their education by the time of marriage. As a result, maternal education remained the same for all the siblings in the family. As shown at the beginning of this section (Table 5), controlling for maternal longevity does not result in disappearance of the effects of maternal age on longevity. Thus, our study indicates that the maternal age effects on survival found in the within-family analysis are more likely to be related to physiological mechanisms of some sort.

In addition to maternal age, the within-family approach can be applied to the season-of-birth study of exceptional longevity. Month of birth is a useful proxy characteristic for environmental effects acting during in-utero and early infancy development. To analyse net effects of birth month on exceptional longevity, unconfounded by possible changes in birth and infant death seasonality, childhood conditions and genetic background, we conducted a matched study using a multivariate conditional logistic regression method (Gavrilov and Gavrilova 2011). 
The results demonstrate that people born in September-November have significantly higher chances of exceptional longevity than people born in March. This monthof-birth effect is observed even for siblings who survived to age 70, suggesting a very long-lasting influence of season of birth on longevity similar to long-lasting effect of maternal age (Gavrilov and Gavrilova 2011). These results are in agreement with previous publications on the effects of birth month on lifespan in the northern hemisphere (Abel and Kruger 2010; Doblhammer and Vaupel 2001; Doblhammer et al. 2005; Gavrilov and Gavrilova 1999; Lerchl 2004; Vaiserman et al. 2009) and in the United States in particular (Doblhammer 2004; Gavrilov and Gavrilova 2008).

In sum, the results obtained in the within-family studies demonstrate that factors acting early in life may have significant long-lasting effects on survival to advanced ages. These results are consistent with the reliability theory of ageing and the High Initial Damage Load (HIDL) hypothesis in particular (Gavrilov and Gavrilova 1991; Gavrilov and Gavrilova 2004), which emphasises the importance of the initial level of damage in determining future human longevity. A more specific explanation of the observed effects of early-life conditions on longevity can be provided by the inflammation hypothesis suggested by Finch and Crimmins (2004). According to this hypothesis, a strong acute-phase inflammatory response required for survival early in life initiates chronic inflammation, which promotes chronic diseases of ageing.

The within-family approach has great advantages over other methods because it is free of confounding caused by between-family differences. At the same time, this approach allows researchers to analyse a limited number of predictor variables. Only variables that vary across siblings in the family can be analysed. The within-family approach described in this section has a potential to be extended further to include adulthood variables in addition to the early-life conditions.

\section{Sampling centenarians and genetically unrelated controls from the same population universe: the between-family approach}

In this study we analysed early-life and adulthood effects that operate throughout life by comparing centenarians of each gender to their peers who were born in the United States in the same year and died at age 65 . Both cases and controls were randomly sampled from the same population universe (computerised family histories) and had the same birth year window (1890-91) to obtain a homogeneous setting. The records of the selected individuals were linked to historical US censuses (1900, 1910, 1930). The main focus of the study is on the 1900 and 1930 censuses that correspond to the childhood and adulthood periods of their individual lives. The age at death for controls is selected assuming that the majority of deaths at age 65 occur due to chronic age-related diseases rather than to injuries or infectious diseases.

Data quality control procedure in this study included: (1) preliminary quality control of computerised family histories (data consistency checks); (2) verification 
of the centenarian's death date; (3) verification of the birth date (for centenarians and controls); (4) verification of family information (parents, spouses and siblings). The methods of age validation were based on the approaches proposed by the experts in this area (Jeune and Vaupel 1999; Poulain 2010) and our own research experience. All records (for centenarians and controls) were subjected to verification and quality control using several independent data sources including the US Social Security Administration Death Master File (DMF) and birth date verification using early US censuses. ${ }^{6}$

Birth registration by the federal government in the United States was not established until 1902 and the process of establishing birth reports by individual states took from 1915 to 1933 (1959 for Alaska and Hawaii). For this reason, official birth certificates are not available for many individuals born before 1900 in the United States. In our study, we had three independent sources of information about birth date: online family histories, the 1900 census and the Social Security Administration Death Master File. Our sampling procedure required that records in family histories had exact (date, month, year) time-of-birth information, which ensured that it was taken from written sources (family bible, birth certificate, etc.) rather than from recollection, so we consider information on the time of birth date in family history to be a reliable one. Nevertheless, we additionally validated the birth date information by linking records to the 1900 census and the Social Security Administration Death Master File. Only those records were used where there was a consensus between these three independent data sources.

The procedure of death date verification using DMF is not feasible for validating the death dates of controls, because data completeness of DMF is not very high for deaths which occurred before the 1970s. We found that over 65 per cent of deaths in the control group could be confirmed through the US state death indexes, cemetery records and obituaries, which cover longer periods of time. Taking into account that the exact ages of death for controls are not particularly important for the study design, it is possible to rely on death date information recorded in family histories for controls not found in external sources as it was done in the Utah Population Database for individuals who died before 1932 (Kerber et al. 2001).

Verification of birth dates was accomplished through a linkage to the 1900 US census data recorded when the persons were still in child age (when age exaggeration is less common compared to claims of exceptional longevity made at old age). The preference is given to the 1900 census because it is more complete and detailed in regard to birth date verification (e.g. containing information on month and year of birth) than the 1910 and 1920 censuses. If a person cannot be found in the

\footnotetext{
6 According to our experience, the linkage to DMF selects out the majority of incorrect records for alleged centenarians (Gavrilova and Gavrilov 2007). A definite match is established when information on first and last names (spouse's last name for women), day, month and year of birth matches in DMF and family history (Sesso et al. 2000). In case of disagreement in day, month or year of birth, the validity of a match is verified on the basis of additional agreement between place of the last residence and place of death.
} 
1900 census, he/she was searched in the 1910 census. We obtained a good linkage success rate in our study (94-98\%), because of availability of powerful online indexes provided by the Ancestry.com service and supplemental information in family histories. ${ }^{7}$ Data on birth dates, birth places and names of siblings available in family histories produced unambiguous matches in overwhelming majority of cases.

After the linkage of these data to early censuses, the final database on centenarians and controls combined information on family characteristics (taken from family histories), data on the early-life conditions taken from the 1900-1910 US censuses and adult socio-economic status taken from the 1930 Census. Early US censuses contain a rich set of variables, which can be used to study the effects of both childhood and adulthood living conditions on human longevity. Below we summarise the core topical domains of the variables analysed in this study.

Childhood living conditions at household level. This information was obtained from 1900 and 1910 censuses. Selection of variables was guided by the results obtained in previous studies that demonstrated that child mortality is strongly affected by household structure (Preston and Haines 1991). Another important factor of survival to advanced age is childhood farm residence- a result found in our earlier study (Gavrilova and Gavrilov 2007) as well as in other studies (Hill et al. 2000; Preston et al. 1998).

Infectious burden. The main hypothesis we studied here is that the early exposure to infections decreases chances of survival to advanced ages by affecting mortality later in life. The infectious burden is estimated as the within-family infectious burden. Information on children ever born and children survived allowed us to estimate the proportion of surviving children for each family where the biological mother is present. Child mortality served as a proxy of the infectious disease burden in the family characterising the living environment, as suggested by other researchers (Bengtsson and Lindstrom 2000; Bengtsson and Lindstrom 2003; Finch and Crimmins 2004; Preston and Haines 1991). We based our estimates of child mortality on information available in the 1910 census whenever possible, because by this time the majority of studied mothers had finished their reproductive period.

Seasonal early-life conditions. Effects of seasonal conditions on survival to extreme ages are studied using month of birth as an integral proxy for environmental seasonal conditions (e.g. seasonal infections) before and shortly after birth. Existing literature on US mortality and our own results based on the within-family approach show that month of birth may be a significant predictor of mortality not only during childhood but also in later life (Costa and Lahey 2005; Doblhammer 2004; Doblhammer and Vaupel 2001; Gavrilov and Gavrilova 1999; Gavrilov and Gavrilova 2011; see also Section 2).

\footnotetext{
7 Ancestry.com has a powerful search engine which helps researchers find a person in multiple historical sources simultaneously (including all historical US censuses, up to the 1940 one) based on all information available in computerised genealogies. Use of this service greatly facilitates the linkage procedure and helps to obtain unambiguous link in practically all studied cases.
} 
Adulthood social conditions reported in the 1930 census. Socio-economic achievement at adult ages for men was estimated using occupational status and dwelling ownership status (owned or rented property). In particular, we tested the hypothesis that a farming background is particularly favourable for male survival because sons of farmers become farmers as well (Preston et al. 1998). In this case the farming status in both 1900 and 1930 should result in a significant advantage for survival to age 100. In the case of females, the estimation of socio-economic achievements through their occupation is not feasible, because in 1930 the proportion of women in the labour force in the United States was very low. A reasonable proxy variable describing the social status of non-working adult women is the occupation of the husband (for married women) or that of the head of household for single, widowed or divorced women. Urban/rural residence in 1930 is another variable used in the study. Preston and Haines (1991) found that child mortality in 1900 was significantly higher in urban than in rural areas. Urban adults in the contemporary United States also have higher mortality despite better infrastructure and access to health services (Hayward et al. 1997).

Familial longevity and other family characteristics. For this particular study, the most important variables are the lifespans of mother and father. As yet, no studies have simultaneously examined the net effects of parental longevity and early-life conditions. Studies suggest that the effects of parent's longevity on the longevity of their offspring may be substantial (Gavrilov et al. 2002; Kerber et al. 2001; Pearl and Pearl 1934) and heritability of lifespan estimates increase dramatically when parents live longer than 80 years (Gavrilova et al. 1998). Therefore, we believe that parental longevity (measured as a paternal and maternal lifespan of 80 years and over) may have a significant moderating influence on the effects of childhood conditions and can be used as a proxy for genetic influences on lifespan. ${ }^{8}$ Other family variables of interest are paternal and maternal ages at a person's birth as well as sibship size and birth order.

We have identified 836 centenarians born in 1890-91 in the United States and 841 shorter-lived controls born in the US who died at age $65 .{ }^{9}$ Further linkage to the

\footnotetext{
8 Information on parental birth and death dates was taken from computerised family histories. Birth dates of parents were validated using the 1900 and 1910 censuses. In the case of death dates we relied on information available in genealogies as do other genealogical studies (Kerber et al. 2001). According to our experience in working with genealogies, death dates of shorter-lived individuals are reported with significantly better accuracy than death dates of centenarians (probably because there is less opportunity for century misreporting). We were able to check the accuracy of death date reporting for shorter-lived persons using 68 images of original death certificates available for some genealogical records. In all cases (with one exception) the death date in the computerised genealogy was the same as the one reported in the death certificate, confirming a good quality of age reporting in our sample of genealogies.

9 Sample sizes of male centenarians are small in the majority of longevity studies, and in order to resolve this problem and to have a sample balanced in regard to gender, males are oversampled in this study. Note that this oversampling does not affect the analyses because male and female data are
} 
1900 census resulted in a $98.2 \%$ success rate for centenarians and a $98.6 \%$ success rate for controls. $94.9 \%$ of centenarian records and $96.4 \%$ of control records were successfully linked to the 1930 census. Linkage to the 1900 census revealed that $95.6 \%$ centenarians and $96.0 \%$ controls lived with one or both biological parents. $67 \%$ of fathers were farmers according to the 1900 census. Centenarians and controls had approximately equal sibship sizes on average (7.6 and 7.8, respectively), which is higher compared to the general population in 1900 census (5.6). In further analyses we restricted our sample to records where information was available for both the 1900 and 1930 censuses. To study effects of marriage history on survival to age 100 years, only records for individuals who were married in 1930 were taken into account. In the end, the data for 765 centenarians and 783 shorter-lived controls were used in our analyses.

We used uni- and multivariate logistic regression models to study survival to age 100. Our main focus was on the following three types of variables:

(1) Early-life conditions drawn from the 1900 census (type of parental household: farm or non-farm, own or rented, parental literacy, parental immigration status, paternal occupation, number/proportion of children born/survived by mother, size of parental household in 1900 including grandparent or boarder in household, places of birth for household members);

(2) Midlife conditions drawn from the 1930 census (type of person's household, availability of a radio in household, person's marital status and age at first marriage, person's occupation or husband's occupation in the case of women, industry of occupation, number of children in household, veteran status);

(3) Family characteristics drawn from computerised genealogies (paternal and maternal lifespan, paternal and maternal age at person's birth, number of siblings).

In the first step we studied familial, childhood and adulthood variables separately using univariate analyses. The study of familial characteristics taken from genealogies revealed that paternal and maternal longevity was significantly associated with survival to age 100 for both men and women. However, loss of parents early in life (before 1910) had no effect on the chances to become a centenarian. Being born in the second half of the year was significantly associated with male longevity. Larger household size, birth in the Northeast or Midwest regions and having a farmer father were found to be other significant predictors of male (but not female) longevity in univariate analyses. Birth in the Northeast region is predictive for survival to advanced ages in men and this result agrees with findings by Hill et al. (2000) for persons surviving to age 85 . However, this result does not agree with the results of our earlier study, which compared centenarians drawn from computerised family histories to population-based controls (Gavrilova and Gavrilov 2007). Female longevity revealed

studied separately, taking into account that men and women may respond differently to the same set of risk factors. 
Table 7:

Predictors of male survival to age 100: effects of parental longevity, early-life and midlife conditions. Results of multivariate logistic regression

\begin{tabular}{lrrr}
\hline Variable & Odds ratio & $\mathbf{9 5 \%}$ CI & p-value \\
\hline Father lived 80+ & 1.84 & $1.35-2.51$ & $<0.001$ \\
Mother lived 80+ & 1.70 & $1.25-2.32$ & 0.001 \\
Farmer in 1930 & 1.67 & $1.21-2.31$ & 0.002 \\
Born in Northeast region & 2.08 & $1.27-3.40$ & 0.004 \\
Born in second half of year & 1.36 & $1.00-1.84$ & 0.050 \\
Radio in household, 1930 & 0.87 & $0.63-1.19$ & 0.374 \\
\hline
\end{tabular}

$N=723$. Farming childhood in 1900 was found to be a non-significant predictor for males. Calculated using Stata 11 statistical package (procedure logistic).

no significant associations with any of 1900 census variables. The univariate analyses showed further that working as a farmer in 1930 was a very strong predictor of longevity for men. In the case of women, having a farmer for a husband had no effect on the chances of survival to age 100 . For women, availability of a radio in the household was the strongest predictor of longevity among the studied midlife variables.

Table 7 presents the results of our multivariate analyses for men and shows the variables that were predictive for men and/or women. When familial, early-life and midlife characteristics are combined, having a farmer for a father is no longer associated with longevity of men. Parental longevity turned out to be one of the strongest predictors of survival to age 100. Note that the farming occupation in 1930 is one of the strongest predictors of survival to age 100 for men, which is in keeping with the results of other studies including our own study of centenarians based on a population-based sample of survivors to age 100 from the 1887 birth cohort (Gavrilov and Gavrilova 2012).

Table 8 presents results of multivariate analyses for women. For women, having a husband who is a farmer still has no effect on survival to age 100. Just as for men, longevity of parents is a strong predictor of survival to age 100 for women (Table 8). Interestingly, having had a radio in the household in 1930 had a positive effect on longevity for women but not for men. At first glance this result may be due to the positive effect of wealth (proxied by radio in household) on longevity. Indeed, a radio in the household is positively associated with a more direct measure of wealth (living in owned vs rented farm or house) and this association is statistically significant ( $p<0.001$, two-sided chi-square test). However, when this direct measure of wealth (property ownership) is added to the regression model with the predictor variables listed in Tables 7 and 8 it shows no significant relationship with longevity $(\mathrm{OR}=1.04, \mathrm{p}=0.810$ for men; $\mathrm{OR}=1.01, \mathrm{p}=0.938$ for women $)$ while the effect of a radio remains a significant predictor of female longevity $(O R=1.61, p=0.003)$. 
Table 8:

Predictors of female survival to age 100: effects of parental longevity, early-life and midlife conditions. Results of multivariate logistic regression

\begin{tabular}{lrrr}
\hline Variable & Odds ratio & $\mathbf{9 5 \%}$ CI & p-value \\
\hline Father lived 80+ & 2.19 & $1.61-2.98$ & $<0.001$ \\
Mother lived 80+ & 2.23 & $1.66-2.99$ & $<0.001$ \\
Husband (or head of household) & 1.15 & $0.84-1.56$ & 0.383 \\
$\quad$ farmer in 1930 & & & \\
Radio in household, 1930 & 1.61 & $1.18-2.20$ & 0.003 \\
Born in second half of year & 1.18 & $0.89-1.58$ & 0.256 \\
Born in Northeast region & 1.04 & $0.65-1.67$ & 0.857 \\
\hline
\end{tabular}

$N=815$. Calculated using Stata 11 statistical package (procedure logistic).

If the effect of radio is related to household wealth then we also may expect that this effect should be observed for both men and women. It is more likely that this finding can be explained by the fact that women in 1930 spent most of their time at home and were much more exposed to radio broadcasts (as an educational and entertainment source) than men. Listening to the radio improves people's feelings of happiness and energy, and an electro-encephalographic (EEG) study found that listening to the radio creates high levels of positive reactions in the brain (Redican and Barber 2012).

Finally, we tested our previous results that season of birth may be predictive for survival to very old age and compared season of birth among centenarians and shorterlived controls in our database (results not shown). We found that more centenarians than controls were born in the second half of the year and that this difference is statistically significant ( $p=0.032$, chi-square test). This result thus confirms our results obtained using the within-family analysis (see Section 2) showing that centenarians were born more often in September-November.

In sum, this study demonstrated that both midlife and early-life conditions affect survival to age 100 with some gender specificity. It is also important to note that parental longevity turned out to be one of the strongest predictors of survival to age 100. Thus, we may conclude that information about such an important predictor as parental longevity cannot be ignored and should be collected in contemporary longitudinal studies. At the same time, we found no effects of higher child mortality in a household (a proxy of infectious burden) on longevity as suggested by the inflammatory hypothesis of ageing (Finch and Crimmins 2004). 


\section{Conclusions}

In this article, we considered various approaches to study effects of early-life environment and midlife conditions on longevity. Some cases of exceptional longevity may represent particularly interesting outcomes of successful natural experiments in delaying human ageing and preventing age-related diseases. For this reason, such cases may be of special interest for studies on early-life events and conditions of late-life survival. At the same time, studies of centenarians require careful work with regard to age validation and selection of a proper control group. In this paper we considered three different approaches. Two designs take advantage of using biological (siblings) and non-biological (siblings-in-law) relatives as a control group. Siblings-in-law have certain advantages over the general population, which is often used as a control in centenarian studies. Studied samples of centenarians rarely represent the general population. Hence, siblings-in-law having similar socioeconomic background are a more appropriate control group for married subjects.

Use of the within-family design where biological siblings of centenarians serve as a control group has several other advantages over the traditional between-family approach. This approach makes it possible to control for effects of shared family environment during childhood and many parental characteristics. These advantages, however, may become limitations if we are interested in effects of childhood household conditions or parental lifespan on longevity. To address these limitations of the within-family analysis we considered a third approach which allows us to study effects of both early-life and midlife conditions on longevity. This approach is based on drawing a control group from the same source (population universe) as the centenarian group.

Applying these approaches to centenarian data provided results consistent with the results of both our earlier studies and independent studies by other researchers. The within-family study demonstrated that being born to a younger mother increases the chances of becoming a centenarian, which is consistent with our previous study on another sample of centenarians (Gavrilov and Gavrilova 2012) as well as the study of Canadian centenarians (Jarry et al. 2012b). Being born in the second half of the year is beneficial for longevity as shown by both the within-family (Gavrilov and Gavrilova 2011) and the between-family analyses presented in this paper. Farming occupation is another factor, which increases the likelihood of long life as shown by the between-family study presented here as well as by the study based on the population-based sample of centenarians born in 1887 (Gavrilov and Gavrilova 2012). The between-family approach further confirmed that parental longevity is a strong independent predictor of survival to age 100 .

The results summarised in this paper demonstrate that studies on centenarians could become a gold mine for unravelling the secrets of human longevity through careful epidemiological analysis of fortunate unintended natural experiments on lifeextension and disease prevention. The gold mine comparison is appropriate here not only in terms of high gains to be expected for a possible dramatic extension of healthy human life, but also in terms of the required effort: we had to scan over 300,000 online 
family histories and then carry out tedious work on data validation and cleaning in order to obtain just a few hundred reliable records and some meaningful findings. Therefore we consider the results of this study as the beginning of a subsequent large-scale research effort that promises potentially breathtaking findings in the future. For instance, the approaches presented in this paper may be extended further by linking centenarian records and records of their relatives to historical data sources such as early censuses, civil draft registration cards, marriage certificates and other documents.

\section{Acknowledgements}

This study was supported by the U.S. National Institute on Aging (grant R01 AG028620). We are most grateful to the participants of the International conference 'Determinants of Unusual and Differential Longevity' (Vienna, Austria, 21-23 November 2012) for encouraging discussions. Our special thanks to the editors of this edition and to anonymous reviewers for their constructive criticism and useful suggestions.

\section{References}

Abel, E. L., and M. L. Kruger. 2010. "Birth Month Affects Longevity”. Death Studies 34 (8): 757-763. doi:10.1080/07481181003772499.

Adams, J. W., and A. B. Kasakoff. 1984. "Migration and the Family in Colonial New England: The View From Genealogies". Journal of Family History 9 (1): 24-43. doi:10.1177/036319908400900102.

Adkins, G., P. Martin, and L. W. Poon. 1996. "Personality Traits and States as Predictors of Subjective Well-Being in Centenarians, Octogenarians, and Sexagenarians". Psychology and Aging 11 (3): 408-416. doi:10 . 1037 /08827974.11 .3 .408$.

Anderton, D. L., N. O. Tsuya, L. L. Bean, and G. P. Mineau. 1987. "Intergenerational Transmission of Relative Fertility and Life Course Patterns". Demography 24 (4): 467-480. doi:10.2307/2061386.

Barker, D. J. P. 1998. Mothers, Babies, and Health in Later Life. 2nd ed. London: Churchill Livingstone.

Bean, L. L., D. L. Anderton, and G. P. Mineau. 1992. "High Risk Childbearing: Fertility and Infant Mortality on the American Frontier". Social Science History 16: 337-363.

Bell, F. C., A. H. Wade, and S. C. Goss. 1992. Life Tables for the United States Social Security Area, 1900-2080. Actuarial Study 107. Baltimore, MD: U.S. Dept. of Health and Human Services, Social Security Administration, Office of the Actuary. 
Bengtsson, T., and M. Lindström. 2000. "Childhood Misery and Disease in Later Life: The Effects on Mortality in Old Age of Hazards Experienced in Early Life, Southern Sweden, 1760-1894”. Population Studies 54 (3): 263-277. doi:10.1080/ 713779096.

Bengtsson, T., and M. Lindström. 2003. "Airborne Infectious Diseases During Infancy and Mortality in Later Life in Southern Sweden, 1766-1894”. International Journal of Epidemiology 32 (2): 286-294. doi:10.1093/i je/dyg061.

Bickel, S. E. 2005. "Aging (Not So) Gracefully". Nature Genetics 37 (12): 1303-1304. doi:10. 1038/ng1205-1303.

Bouwhuis, S., A. Charmantier, S. Verhulst, and B. C. Sheldon. 2010. "TransGenerational Effects on Ageing in a Wild Bird Population". Journal of Evolutionary Biology 23 (3): 636-642. doi:10 . 1111/ j . 1420-9101 . 2009 . Q1929.x.

Breslow, N. 1970. "A Generalized Kruskal-Wallis Test for Comparing K Samples Subject to Unequal Patterns of Censorship". Biometrika 57 (3): 579-594. doi:10. 1093/biomet/57.3.579.

Breslow, N., and N. E. Day. 1993. Statistical methods in cancer research. Volume 1: The analysis of case-control studies. Paperback reprint. IARC Scientific Publications 32. Oxford: Oxford University Press.

Carnes, B. A., R. Riesch, and I. Schlupp. 2012. "The Delayed Impact of Parental Age on Offspring Mortality in Mice". The Journals of Gerontology. Series A: Biological Sciences and Medical Sciences 67 (4): 351-357. doi:10. 1093/gerona/glr116.

Caselli, G., L. Pozzi, J. W. Vaupel, L. Deiana, G. Pes, C. Carru, C. Franceschi, and G. Baggio. 2006. "Family Clustering in Sardinian Longevity: A Genealogical Approach". Experimental Gerontology 41 (8): 727-736. doi:10. 1016/j . exger . 2006.05 .009$.

Comings, D. E., and J. MacMurray. 2001. "Maternal Age as a Confounding Variable in Association Studies". American Journal of Medical Genetics Part B: Neuropsychiatric Genetics 105 (7): 564.

Comings, D. E., and J. P. MacMurray. 2006. "Maternal Age at the Birth of the First Child as an Epistatic Factor in Polygenic Disorders". American Journal of Medical Genetics Part B: Neuropsychiatric Genetics 141B (1): 1-6. doi:10.1002/ajmg. b. 30026.

Costa, D. L., and J. Lahey. 2005. "Becoming Oldest-Old: Evidence From Historical U.S. Data". Genus 61: 125-161.

Dior, U. P., H. Hochner, Y. Friedlander, R. Calderon-Margalit, D. Jaffe, A. Burger, M. Avgil, O. Manor, and U. Elchalal. 2013. "Association Between Issue of Children and Mortality of Mothers: Results of a 37-Year Follow-Up Study". Annals of Epidemiology 23 (1): 13-18. doi:10.1016/j . annepidem. 2012 . 10.005.

Doblhammer, G. 2004. The Late Life Legacy of Very Early Life. Demographic Research Monographs 2. Heidelberg: Springer. 
Doblhammer, G., R. Scholz, and H. Maier. 2005. "Month of Birth and Survival to Age 105+: Evidence From the Age Validation Study of German SemiSupercentenarians". Experimental Gerontology 40 (10): 829-835. doi:10.1016/ j.exger.2005.07.012.

Doblhammer, G., and J. W. Vaupel. 2001. "Lifespan Depends on Month of Birth". Proceedings of the National Academy of Sciences 98 (5): 2934-2939. doi:10. 1073/pnas. 041431898.

Elo, I. T., and S. H. Preston. 1992. "Effects of Early-Life Conditions on Adult Mortality: A Review”. Population Index 58 (2): 186-222. doi:10.2307/3644718.

Elo, I. T., S. H. Preston, I. Rosenwaike, M. Hill, and T. P. Cheney. 1996. "Consistency of Age Reporting on Death Certificates and Social Security Records Among Elderly African Americans”. Social Science Research 25 (3): 292-307. doi:10. 1006/ssre. 1996.0014.

Finch, C. E., and E. M. Crimmins. 2004. "Inflammatory Exposure and Historical Changes in Human Life-Spans". Science 305 (5691): 1736-1739. doi:10.1126/ science. 1092556.

Fogel, R. W., and D. L. Costa. 1997. "A Theory of Technophysio Evolution, With Some Implications for Forecasting Population, Health Care Costs, and Pension Costs". Demography 34 (1): 49-66. doi:10.2307/2061659.

Gagnon, A., K. R. Smith, M. Tremblay, H. Vézina, P.-P. Paré, and B. Desjardins. 2009. "Is There a Trade-Off Between Fertility and Longevity? A Comparative Study of Women From Three Large Historical Databases Accounting for Mortality Selection". American Journal of Human Biology 21 (4): 533-540. doi:10.1002/ ajhb. 20893.

Gavrilov, L. A., and N. S. Gavrilova. 1991. The Biology of Life Span: A Quantitative Approach. New York: Harwood Academic.

Gavrilov, L. A., and N. S. Gavrilova. 1999. "Season of Birth and Human Longevity". Journal of Anti-Aging Medicine 2 (4): 365-366. doi:10.1089/rej . 1. 1999. 2 . 365.

Gavrilov, L. A., and N. S. Gavrilova. 2001a. "Biodemographic Study of Familial Determinants of Human Longevity". Population (English Edition) 13 (1): 197-222.

Gavrilov, L. A., and N. S. Gavrilova. 2001b. "Human Longevity and Parental Age at Conception". In Sex and Longevity: Sexuality, Gender, Reproduction, Parenthood, ed. by J.-M. Robine, T. B. L. Kirkwood, and M. Allard, 7-31. Research and Perspectives in Longevity. Berlin, Heidelberg: Springer.

Gavrilov, L. A., and N. S. Gavrilova. 2001c. "The Reliability Theory of Aging and Longevity". In Handbook of the Biology of Aging, ed. by E. J. Masoro and S. N. Austad. San Diego: Academic Press.

Gavrilov, L. A., and N. S. Gavrilova. 2001d. "The Reliability Theory of Aging and Longevity". Journal of Theoretical Biology 213 (4): 527-545. doi:10. 1006/j tbi . 2001.2430 . 
Gavrilov, L. A., and N. S. Gavrilova. 2003a. "Early-Life Factors Modulating Lifespan". In Modulating Aging and Longevity, ed. by S. I. Rattan, 27-50. Dordrecht, The Netherlands: Kluwer Academic.

Gavrilov, L. A., and N. S. Gavrilova. 2003b. "The Quest for a General Theory of Aging and Longevity”. Science of Aging Knowledge Environment 2003 (28): 6. doi:10.1126/sageke.2003.28.re5.

Gavrilov, L. A., and N. S. Gavrilova. 2004. "Early-Life Programming of Aging and Longevity: The Idea of High Initial Damage Load (The HIDL Hypothesis)". Annals of the New York Academy of Sciences 1019 (1): 496-501. doi:10.1196/ annals.1297.091.

Gavrilov, L. A., and N. S. Gavrilova. 2008. "Mortality Measurement at Advanced Ages: A Study of the Social Security Administration Death Master File". In Living to 100 and beyond: Survival at advanced ages [SOA online monograph M-LIO8-1], 32. Schaumburg, IL: The Society of Actuaries (SOA).

Gavrilov, L. A., and N. S. Gavrilova. 2011a. "Mortality Measurement at Advanced Ages: A Study of the Social Security Administration Death Master File". North American Actuarial Journal: 432-447.

Gavrilov, L. A., and N. S. Gavrilova. 2011b. "Season of Birth and Exceptional Longevity: Comparative Study of American Centenarians, Their Siblings, and Spouses". Journal of Aging Research 2011: 1-11. doi:10 . 4061/2011/104616.

Gavrilov, L. A., and N. S. Gavrilova. 2012. "Biodemography of Exceptional Longevity: Early-Life and Mid-Life Predictors of Human Longevity". Biodemography and Social Biology 58 (1): 14-39. doi:10 . 1080/19485565 . 2012.666121.

Gavrilov, L. A., N. S. Gavrilova, S. J. Olshansky, and B. A. Carnes. 2002. "Genealogical Data and the Biodemography of Human Longevity". Social Biology 49 (3): 160-173.

Gavrilov, L. A., N. S. Gavrilova, V. G. Semenova, G. N. Evdokushkina, E. V. Lapshin, V. N. Krutko, and A. L. Gavrilova. 1997. "Maternal Age and Offspring Longevity". Doklady Akademii Nauk 354 (4): 569-572.

Gavrilova, N. S., and L. A. Gavrilov. 2007. "Search for Predictors of Exceptional Human Longevity: Using Computerized Genealogies and Internet Resources for Human Longevity Studies". North American Actuarial Journal 11 (1): 49-67.

Gavrilova, N. S., L. A. Gavrilov, G. N. Evdokushkina, V. G. Semyonova, A. L. Gavrilova, N. N. Evdokushkina, Y. E. Kushnareva, V. N. Kroutko, and A. AYu. 1998. "Evolution, Mutations, and Human Longevity: European Royal and Noble Families". Human Biology 70 (4): 799-804.

Gloria-Bottini, E., E. Cosmi, M. Nicotra, E. V. Cosmi, and E. Bottini. 2005. "Is Delayed Childbearing Changing Gene Frequencies in Western Populations?" Human Biology 77 (4): 433-441. 
Hadley, E. C., K. Rossi Winifred, S. M. Albert, J. Bailey-Wilson, J. Baron, R. Cawthon, J. C. Christian, E. H. Corder, C. Franceschi, B. Kestenbaum, L. Kruglyak, D. Lauderdale, J. Lubitz, G. M. Martin, G. E. McClearn, M. McGue, T. Miles, G. Mineau, G. Quellette, N. Pedersen, S. H. Preston, W. F. Page, Province, M., F. Schächter, N. J. Schork, and J. W. Vaupel. 2000. "Genetic Epidemiologic Studies on Age-Specified Traits". Ed. by NIA Aging and Genetic Epidemiology Working Group. American Journal of Epidemiology 152 (11): 1003-1008. doi:10.1093/ aje/152.11.1003.

Hagberg, B., B. B. Alfredson, L. W. Poon, and A. Homma. 2001. "Cognitive Functioning in Centenarians a Coordinated Analysis of Results From Three Countries". The Journals of Gerontology. Series B: Psychological Sciences and Social Sciences 56 (3): P141-P151. doi:10. 1093/geronb/56.3.P141.

Hayward, M. D., and B. K. Gorman. 2004. "The Long Arm of Childhood: The Influence of Early-Life Social Conditions on Men's Mortality". Demography 41 (1): 87-107. doi:10.1353/dem. 2004.0005.

Hayward, M. D., A. M. Pienta, and D. K. McLaughlin. 1997. "Inequality in Men's Mortality: The Socioeconomic Status Gradient and Geographic Context". Journal of Health and Social Behavior 38 (4): 313-330. doi:10.2307/2955428.

Heffner, L. J. 2004. “Advanced Maternal Age-How Old Is Too Old?" The New England Journal of Medicine 351 (19): 1927-1929. doi:10. 1056/NEJMp048087.

Hill, M. E., S. H. Preston, I. Rosenwaike, and J. F. Dunagan. 2000. Childhood Conditions Predicting Survival to Advanced Age Among White Americans. Presented at the Annual Meeting of the Population Association of America, Los Angeles, 23-25 March 2000.

Hosmer, D. W., and S. Lemeshow. 2001. Applied Logistic Regression. New York: John Wiley \& Sons.

Hubbard, R. E., M. K. Andrew, and K. Rockwood. 2009. "Effect of Parental Age at Birth on the Accumulation of Deficits, Frailty and Survival in Older Adults". Age and Ageing 38 (4): 380-385. doi:10. 1093/ageing/afp035.

Jalavisto, E. 1950. "The Influence of Parental Age on the Expectation of Life". Revue Médicale De Liège 5 (20): 719-722.

Jarry, V., A. Gagnon, and R. Bourbeau. 2012a. To What Extent Is Exceptional Longevity Associated With Parental Age at Childbirth and Birth Order? Presented at International Conference on Determinants of Unusual and Differential Longevity, Vienna, November 2012.

Jarry, V., A. Gagnon, and R. Bourbeau. 2012b. "Survival Advantage of Siblings and Spouses of Centenarians in 20th-Century Quebec". Canadian Studies in Population 39 (3): 67-78.

Jeune, B., and J. W. Vaupel. 1999. Validation of Exceptional Longevity. Monographs on Population Aging 6. Odense: Odense University Press. 
Kalmijn, M., and G. Kraaykamp. 2005. "Late or Later? A Sibling Analysis of the Effect of Maternal Age on Children's Schooling”. Social Science Research 34 (3): 634-650. doi:10.1016/j.ssresearch.2004.04.008.

Keefe, D. L., S. Franco, L. Liu, J. Trimarchi, B. Cao, S. Weitzen, S. Agarwal, and M. A. Blasco. 2005. "Telomere Length Predicts Embryo Fragmentation After in Vitro Fertilization in Women-Toward a Telomere Theory of Reproductive Aging in Women". American Journal of Obstetrics and Gynecology 192 (4): 1256-1260. doi:10.1016/j .ajog. 2005.01.036.

Kemkes-Grottenthaler, A. 2004. "Parental Effects on Offspring Longevity-Evidence From 17th to 19th Century Reproductive Histories". Annals of Human Biology 31 (2): 139-158. doi:10.1080/03014460410001663407.

Kerber, R. A., E. O'Brien, K. R. Smith, and R. M. Cawthon. 2001. "Familial Excess Longevity in Utah Genealogies". The Journals of Gerontology. Series A: Biological Sciences and Medical Sciences 56 (3): B130-B139. doi:10. 1093/gerona/56. 3. B130.

Kuh, D., and Y. Ben-Shlomo. 1997. A Life Course Approach to Chronic Disease Epidemiology. Oxford: Oxford University Press.

Lerchl, A. 2004. "Month of Birth and Life Expectancy: Role of Gender and Age in a Comparative Approach". Naturwissenschaften 91 (9): 422-425. doi:10.1007/ s00114-004-0553-5.

Margrett, J., P. Martin, J. L. Woodard, L. S. Miller, M. MacDonald, J. Baenziger, I. C. Siegler, A. Davey, and L. Poon. 2010. "Depression Among Centenarians and the Oldest Old: Contributions of Cognition and Personality". Gerontology 56 (1): 93-99. doi:10.1159/000272018.

Martin, P., J. Cho, and L. Poon. 2010. "Personality, Functional Capacity, and WellBeing Among Centenarians". Gerontologist 50: 50.

Mazan, R., and A.-G. Gagnon. 2007. "Familial and Environmental Influences on Longevity in Historical Quebec". Population (English Edition) 62 (2): 271-291. doi:10.3917/pope. 702.0271.

Modin, B. 2002. "Birth Order and Mortality: A Life-Long Follow-Up of 14,200 Boys and Girls Born in Early 20th Century Sweden". Social Science $\mathcal{E}$ Medicine 54 (7): 1051-1064. doi:10.1016/S0277-9536(01)00080-6.

Montesanto, A., V. Latorre, M. Giordano, C. Martino, F. Domma, and G. Passarino. 2011. "The Genetic Component of Human Longevity: Analysis of the Survival Advantage of Parents and Siblings of Italian Nonagenarians". European Journal of Human Genetics 19 (8): 882-886. doi:10.1038/ejhg. 2011.40.

Murabito, J. M., R. Yuan, and K. L. Lunetta. 2012. "The Search for Longevity and Healthy Aging Genes: Insights From Epidemiological Studies and Samples of Long-Lived Individuals". The Journals of Gerontology Series A: Biological Sciences and Medical Sciences 67 (5): 470-479. doi:10. 1093/gerona/gls089. 
Myrskylä, M., and A. Fenelon. 2012. "Maternal Age and Offspring Adult Health: Evidence From the Health and Retirement Study". Demography 49 (4): 1231-1257. doi:10.1007/s13524-012-0132-x.

Myrskylä, M., K. Silventoinen, P. Tynelius, and F. Rasmussen. 2013. "Is Later Better or Worse? Association of Advanced Parental Age With Offspring Cognitive Ability Among Half a Million Young Swedish Men". American Journal of Epidemiology 177 (7): 649-655. doi:10.1093/aje/kws237.

Pearl, R., and R. D. W. Pearl. 1934. The Ancestry of the Long-Lived. Baltimore: John Hopkins Press.

Pellestor, F., T. Anahory, and S. Hamamah. 2005. "Effect of Maternal Age on the Frequency of Cytogenetic Abnormalities in Human Oocytes". Cytogenetic and Genome Research 111 (3): 206-212. doi:10.1159/000086891.

Perls, T. T., I. V. Kohler, S. Andersen, E. Schoenhofen, J. Pennington, R. Young, D. Terry, and I. T. Elo. 2007. "Survival of Parents and Siblings of Supercentenarians". The Journals of Gerontology. Series A: Biological Sciences and Medical Sciences 62 (9): 1028-1034.

Perls, T. T., and D. Terry. 2003. "Genetics of Exceptional Longevity". Experimental Gerontology 38 (7): 725-730. doi:10. 1016/S0531-5565(03)00098-6.

Polani, P. E., and J. A. Crolla. 1991. "A Test of the Production Line Hypothesis of Mammalian Oogenesis". Human Genetics 88 (1): 64-70. doi:10 . 1007 / BF00204931.

Poulain, M. 2010. "On the Age Validation of Supercentenarians". In Supercentenarians, ed. by H. Maier, J. Gampe, B. Jeune, J.-M. Robine, and J. W. Vaupel, 3-30. Demographic Research Monographs 7. Springer Berlin Heidelberg.

Poulain, M. 2011. "Exceptional Longevity in Okinawa: A Plea for In-Depth Validation". Demographic Research 25 (7): 245-284. doi:10 . 4054 / DemRes . 2011.25.7.

Preston, S. H., M. E. Hill, and G. L. Drevenstedt. 1998. "Childhood Conditions That Predict Survival to Advanced Ages Among African-Americans". Social Science E Medicine 47 (9): 1231-1246.

Preston, S. H., and M. R. Haines. 1991. Fatal Years: Child Mortality in Late Nineteenth-Century America. Princeton, N.J.: Princeton University Press.

Redican, S., and M. Barber. 2012. Radio: The Emotional Multiplier. London: Radio Advertising Bureau (rab).

Riley, J. 2003. "Did Mothers Begin With an Advantage? A Study of Childbirth and Maternal Health in England and Wales, 1778-1929". Population Studies 57 (1): 5-20. doi:10.1080/0032472032000061695.

Robine, J.-M., A. Cournil, N. Henon, and M. Allard. 2003. "Have Centenarians Had Younger Parents Than the Others?" Experimental Gerontology 38 (4): 361-365. 
Rosenwaike, I., and L. F. Stone. 2003. "Verification of the Ages of Supercentenarians in the United States: Results of a Matching Study". Demography 40 (4): 727-739.

Ruggles, S. 2007. "The Decline of Intergenerational Coresidence in the United States, 1850 to 2000". American Sociological Review 72 (6): 964-989. doi:10.1177/ 000312240707200606 .

Ruggles, S., J. T. Alexander, K. Genadek, R. Goeken, M. B. Schroeder, and M. Sobek. 2010. Integrated Public Use Microdata Series (IPUMS): Version 5.0. [Machinereadable database]. Minneapolis, MN.: University of Minnesota.

Schoenmaker, M., A. J. M. de Craen, P. de Meijer, M. Beekman, G. J. Blauw, P. E. Slagboom, and R. G. J. Westendorp. 2006. "Evidence of Genetic Enrichment for Exceptional Survival Using a Family Approach: The Leiden Longevity Study". European Journal of Human Genetics 14 (1): 79-84. doi:10 . 1038/s j . ejhg . 5201508.

Sebastiani, P., N. Solovieff, A. T. DeWan, K. M. Walsh, A. Puca, S. W. Hartley, E. Melista, S. Andersen, D. A. Dworkis, J. B. Wilk, R. H. Myers, M. H. Steinberg, M. Montano, C. T. Baldwin, J. Hoh, and T. T. Perls. 2012. "Genetic Signatures of Exceptional Longevity in Humans". PLoS ONE 7 (1): 1-22. doi:10.1371/ journal. pone.0029848.

Sesso, H. D., R. S. Paffenbarger, and I.-M. Lee. 2000. "Comparison of National Death Index and World Wide Web Death Searches". American Journal of Epidemiology 152 (2): 107-111. doi:10.1093/aje/152 .2.107.

Shrestha, L. B., and I. Rosenwaike. 1996. "Can Data From the Decennial Census Measure Trends in Mobility Limitation Among the Aged?" The Gerontologist 36 (1): 106-109. doi:10.1093/geront/36.1.106.

Sklar, D., and A. Trachtenberg. 2002. PHP Cookbook. O'Reilly Media, Inc.

Smith, K. R., A. Gagnon, R. M. Cawthon, G. P. Mineau, R. Mazan, and B. Desjardins. 2009a. "Familial Aggregation of Survival and Late Female Reproduction". The Journals of Gerontology. Series A: Biological Sciences and Medical Sciences 64 (7): 740-744. doi:10.1093/gerona/glp055.

Smith, K. R., G. P. Mineau, G. Garibotti, and R. Kerber. 2009b. "Effects of Childhood and Middle-Adulthood Family Conditions on Later-Life Mortality: Evidence From the Utah Population Database, 1850-2002". Social Science E Medicine 68 (9): 1649-1658. doi:10.1016/j . socscimed.2009.02.010.

StataCorp. 2009. Stata User's Guide. Tech. rep. Stata Press.

Strong, L. C., and F. N. Johnson. 1964. "Longevity of Mice Influenced by Maternal Age". Experimental Gerontology 1: 21-30.

Tarín, J. J., V. Gómez-Piquer, F. Rausell, S. Navarro, C. Hermenegildo, and A. Cano. 2005. "Delayed Motherhood Decreases Life Expectancy of Mouse Offspring". Biology of Reproduction 72 (6): 1336-1343. doi:10 . 1095/biolreprod . 104 . Q38919. 
Vaiserman, A. M., M. D. Khalangot, B. Carstensen, M. D. Tronko, V. I. Kravchenko, V. P. Voitenko, L. V. Mechova, N. M. Koshel, and P. E. Grigoriev. 2009. "Seasonality of Birth in Adult Type 2 Diabetic Patients in Three Ukrainian Regions". Diabetologia 52 (12): 2665-2667. doi:10. 1007/s00125-009-1519-0.

Westendorp, R. G. J., D. van Heemst, M. P. Rozing, M. Frölich, S. P. Mooijaart, G.-J. Blauw, M. Beekman, B. T. Heijmans, A. J. M. de Craen, P. E. Slagboom, and Leiden Longevity Study Group. 2009. "Nonagenarian Siblings and Their Offspring Display Lower Risk of Mortality and Morbidity Than Sporadic Nonagenarians: The Leiden Longevity Study". Journal of the American Geriatrics Society 57 (9): 1634-1637. doi:10.1111/j .1532-5415.2009.02381.x.

Willcox, B. J., D. C. Willcox, Q. He, J. D. Curb, and M. Suzuki. 2006. "Siblings of Okinawan Centenarians Share Lifelong Mortality Advantages". The Journals of Gerontology. Series A: Biological Sciences and Medical Sciences 61A (4): 345-354.

Woodward, M. 2005. Epidemiology: Study Design and Data Analysis. Boca Raton, Fla.: Chapman \& Hall/CRC.

Zeng, Y., L. Cheng, H. Chen, H. Cao, E. R. Hauser, Y. Liu, Z. Xiao, Q. Tan, X.-L. Tian, and J. W. Vaupel. 2010. "Effects of FOXO Genotypes on Longevity: A Biodemographic Analysis". The Journals of Gerontology. Series A: Biological Sciences and Medical Sciences 65 (12): 1285-1299. doi:10 . 1093 / gerona / glq156. 